ANLICHM PHF S1872

FULLERE:NES AS PRECURSORS FOR DIAMOND FULM

GROWTH WITHOUT HYDROGEN OR OXYGEN ADDITIONS*

\author{
Dieter M. Gruen, Shengzhong Liu, Alan R. Krauss, \\ Jianshu Luo, and Xianzheng Pan \\ Materials Science, Chemistry, and Chemical Technology Divisions \\ Argonne National Laboratory \\ Argonne, Illinois 60439
}

October 1993

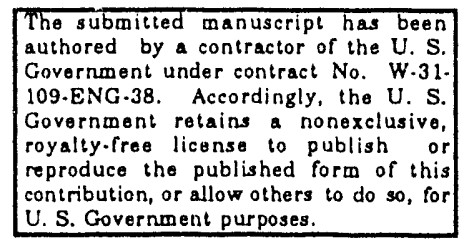

\title{
DISCLAIMER
}

\begin{abstract}
This report was prepared as an account of work sponsored by an agency of the United States Government. Neither the United States Government nor any agency thereof, nor any of their employees, makes any warranty, express or implied, or assumes any legal liability or responsibility for the accuracy, completeness, or usefulness of any information, apparatus, product, or process disclosed, or represents that its use would not infringe privately owned rights. Reference herein to any specific commercial product, process, or service by trade name, trademark, manufacturer, or otherwise does not necessarily constitute or imply its endorsement, recommendation, or favoring by the United States Government or any agency thereof. The views and opinions of authors expressed herein do not necessarily state or reflect those of the United States Government or any agency thereof.
\end{abstract}

\footnotetext{
*Work supported by the U.S. Department of Energy, BES-Materials Sciences, Division of Advanced Energy Projects, under Contract W-31-109-ENG-38.
} 


\section{FULLERENES AS PRECURSORS FOR DIAMOND FILM GROWTH WITHOUT HYDROGEN OR OXYGEN ADDITIONS}

Dieter M. Gruen, Shengzhong Liu, Alan R. Krauss, Jianshu Luo, Xianzheng Pan Materials Science, Chemistry and Chemical Technology Divisions, Argonne National Laboratory, 9700 S. Cass Avenue, Argonne, IL 60439-4831, USA

Diamond films are predominantly grown using one percent or so of a hydrocarbon precursor in hydrogen gas. Hydrogen is generally believed to be necessary for the diamond thin film growth process. However, hydrogen in varying amounts is inevitably incorporated in the growing diamond lattice, leading to structural defects. We report here for the first time the successful growth of diamond films using fullerene precursors in an argon microwave plasma, a unique development achieved without the addition of hydrogen or oxygen. We speculate that collisional fragmentation of $C_{60}$ to give $C_{2}$ could be responsible for the high growth rate of the very fine grained diamond films.

The combination of outstanding physical properties of diamond: its exceptional hardness, thermal conductivity, electrical resistance, chemical inertness, optical transmittance, electrical carrier mobility and dielectric breakdown strength among others has led to a worldwide effort to optimize thin film growth of diamond by chemical vapor deposition (CVD) techniques ${ }^{1}$. For the most part, CVD diamond 
films have been grown in the presence of a large excess of hydrogen using less than $5 \%$ methane as a precursor and often with the addition of small amounts of oxygen. Although it is known that hydrogen incorporated in the diamond lattice during growth introduces defects, hydrogen is generally believed to be an absolutely necessary constituent for CVD diamond growth, based on experimental results ${ }^{2}$ and the theoretical elaboration of growth mechanisms ${ }^{2-5}$. Attempts to grow diamond films at lower hydrogen concentration have up to now mei with little success. For example, Eversole 6 was able to prepare diamond using $\mathrm{CO}$ and $\mathrm{CO}_{2}$ after exposing the initially produced deposits periodically to hydrogen in order to remove non-diamond carbon. $\mathrm{CH}_{4}-\mathrm{Ar}$ and $\mathrm{CH}_{4}-\mathrm{He}$ systems ${ }^{7}$ have also been employed but resulted only in graphite or diamondlike-carbon (DLC) films. Again Mucha et al. 8 also using $\mathrm{CH}_{4}-\mathrm{He}$ mixtures found that selective growth of diamond films occurred only when a $\mathrm{CH}_{4}-\mathrm{He}$ discharge was alternated with an $\mathrm{H}_{2}-\mathrm{O}_{2}-\mathrm{He}$ discharge. Hibshman ${ }^{9}$ explored the lower limit of hydrogen required for diamond formation in the $\mathrm{CO}-\mathrm{H}_{2}$ system and found it to be $0.5 \%$. By analyzing an extensive array of diamond CVD methods used over the last 30 years, Bachmann et al. ${ }^{10}$ concluded that the nature of the precursor molecule is a minor variable in diamond film formation and rationalized a wide variety of data solely on the basis of the carbon, hydrogen, oxygen or halogen ratios. Their ternary phase diagrams delineate a narrow composition regime conducive to diamond growth. All mechanisms proposed up to now require atomic hydrogen to abstract hydrogen from hydrogen-containing carbon 
species attached to the growing diamond surface. It is generally accepted that such hydrogen abstraction reactions are necessary steps leading to the incorporation of carbon into the diamond lattice $2-5$.

It occurred to us that the fascinating all-carbon molecule $C_{60}$ and higher fullerenes which have become available in macroscopic quantities in recent years ${ }^{1-12}$ might serve as non-hydrogenic precursors for diamond growth. Results of this work in which $\mathrm{Ar}-\mathrm{H}_{2}$ fullerene gas mixtures were used to grow diamond films have been communicated (Gruen, D. M., Liu, S., Krauss, A. R. \& Pan, X. Appl. Phys. Lett. submitted). We now wish to report for the first time the successful growth of diamond films without hydrogen or oxygen additions from Ar-fullerene plasmas.

A modified ASTeX microwave plasma deposition system was used for diamond growth (Gruen, D. M., Liu, S., Krauss, A. R. \& Pan, X. Appl. Phys. Lett. submitted). Briefly, fullerene-containing soot which had been treated with methanol to remove hydrocarbon constituents and which had subsequently been thorouglly degassed was placed in a sublimator located in a sidearm of the plasma deposition chamber. Fullerene vapor was introduced into the plasma chamber by heating the sublimator to $550^{\circ} \mathrm{C}$ while flowing $\mathrm{Ar}$ carrier gas through it. Assuming saturation, the estimated atomic carbon content of the $\mathrm{Ar}$ carrier gas, based on the vapor pressure of pure $\mathrm{C}_{60}$, is $0.14 \%$. The $\mathrm{Ar}$ flow rate was regulated at $20 \mathrm{sccm}$ while the total pressure in the chamber was controlled at 100 Torr. Single-crystal silicon (100) substrates mechanically polished with $0.1 \mu \mathrm{m}$ diamond powder were 
placed on a graphite stage and deposition was carried out at $850^{\circ} \mathrm{C}$ with $1500 \mathrm{~W}$ of microwave power for 1-3 hours. The as-deposited films are uniform, reflective and highly resistive. Based on crosssection scanning electron microscope (SEM) images, it is estimated that the growth rate is about $1.2 \mu \mathrm{m} /$ hour, which is higher than, or at least comparable to that commonly observed using $1 \%$ methane in hydrogen as a precursor under similar deposition conditions. Film characterization has made use of X-ray diffraction (XRD), electron diffraction, TEM and SEM imaging, electron energy loss spectroscopy (EELS) and Raman spectroscopy. The following measurements were taken on a typical film after three hours of deposition: X-ray diffraction with a copper $\mathrm{K} \alpha$ source shows three major diamond peaks corresponding to the (111), (220) and (311) reflections respectively, as shown in Figure 1, while Figure 2 displays a selected area (about $4 \mu \mathrm{m}$ in diameter) electron diffraction pattern obtained via TEM. This pattern can be fully indexed to the face-centered cubic diamond lattice with an average lattice constant of $3.53 \AA$. Considering the experimental error of this type of measurement $(5 \%)$, this value is in good agreement with that obtained from single crystal diamond $(3.56 \AA)$ via $\mathrm{X}$-ray diffraction. TEM imaging (Figure 2) reveals a fine-grained deposit with a smaller defect density compared to films prepared at $300 \mathrm{mTorr}$ with a magnetized plasma using $\mathrm{CH}_{4}-\mathrm{H}_{2}-\mathrm{O}_{2}$ mixtures (Gruen, D., Pan, X., Krauss, A. \& Liu, S. manuscript submitted to J. Vac. Sci. Tech. (A)). The grain size appears to be very small, averaging about $0.05 \mu \mathrm{m}$ with the largest grains about $0.3 \mu \mathrm{m}$. The intergranular boundaries are free of graphitic 
phase. Electron energy loss spectroscópy has also been employed for characterization. It is known that different carbon species have very distinct K-absorption edge structures 13. Diamond, an $\mathrm{sp}^{3}$ skeleton, has a single loss feature with an onset at about $289 \mathrm{eV}$ due to its $\sigma *$ electronic states, while graphite -- an $\mathrm{sp}^{2}$ framework -- has an additional absorption starting at about $285 \mathrm{eV}$ owing to its lowerlying antibonding $\pi^{*}$ states. Amorphous carbon and various hydrogenated amorphous carbon films prepared by plasma deposition have a common peak at about $285 \mathrm{eV}^{13}$, much like graphite. Figure 4 shows the electron energy loss spectrum acquired over an area $\sim 2.5 \mu \mathrm{m}$ in diameter. It is clear that our films have no loss feature at $285 \mathrm{eV}$, demonstrating the lack of graphitic or amorphous phases. On the contrary, they display only an absorption peak at $291 \mathrm{eV}$, characteristic of diamond. Raman spectra (figure 5) show a band centered at $1333 \mathrm{~cm}^{-1}$ and a broad feature at about $1550 \mathrm{~cm}^{-1}$. The $1333 \mathrm{~cm}^{-1}$ band with a FWHM of about $17 \mathrm{~cm}^{-1}$ is characteristic of band widths observed with small grain size diamond films ${ }^{14}$. The $1550 \mathrm{~cm}^{-1}$ peak is also commonly observed with small grain diamond films ${ }^{15}$. On the basis of these results, we have concluded that fullerenes can serve as precursors for CVD diamond film growth without the addition of hydrogen or oxygen.

Clearly, a growth mechanism not dependent on hydrogen abstraction reactions must be at work. Additional experiments are underway to elucidate in detail the kinetics and mechanism involved in the novel growth process accompanying the use of fullerene precursors. It is entirely possible that both new growth mechanisms and new growth 
species have to be invoked. In-situ optical measurements reveal very intense $C_{2}$ Swan band emission, and we speculate that $C_{2}$, produced as a result of collisional and other fragmentation processes ${ }^{16}$, may be an important growth species responsible for the quite high growth rates seen in the present work. It should be noted that the diamond film growth reported here starting with fullerene-containing soot is a totally different process from the diamond nucleation enhancement observed with carbon clusters, especially $\mathrm{C}_{70} 17-18$. It would, of course, be of interest to combine the nucleation enhancement stage and the growth step, using fullerenes for both processes. A full characterization of the diamond films produced from $\mathrm{C}_{60}$ with regard to hydrogen content, optical, electrical, thermal conductivity and other properties still remains to be accomplished. It is not unlikely however that diamond film growth without hydrogen addition could result in a material with unique properties. In the event, $\mathrm{C}_{60}$ and other fullerenes could become important new precursors for the production of diamond films.

1. Koshland, D. E. Jr. Science 250, 1637 (1990).

2. for a review, see Pehrsson, P. E., Celii, F. G. \& Butler J. E. in Diamond Films and Coatings (eds Davis, R. D.) 68-146 (Noyes Publications, 1993).

3. Yang, Y. L., Struck, L. M., Sutcu, L. F. \& D'Evelyn, M. P. Thin Solid Films 225, $203-$ $211(1993)$.

4. Piekarczyk, W. \& Prawer, S. Diamond and Related Materials 2, 41-47 (1993).

5. Harris, S. J. \& Goodwin, D. G. J. Phys. Chem. 97, 23-28 (1993).

6. Eversole, W. U.S. Patents 3030187, 3030188, 1962 (filed 1959).

7. Matsumoto, O. \& Katagiri, T. Thin Solid Films 146, 283-289 (1987).

8. Mucha, J. A. \& Flamm, D. L. \& Ibbotson, D. E. J. Appl. Phys. 65, 3448-3452 (1989).

9. Hibshman, H. J. U.S. Patent 3371996 (1968).

10. Bachmann, P. K., Leers, D. \& Lydtin, H. Diamond and Related Materials 1, 1-12 (1991).

11. Kratschmer, W., Lamb, L. D., Fostiropoulas, K. \& Huffman, D. R. Nature 347, 354358 (1990). 
12. Parker, D. H., Wurtz, P., Chatterjee, K., Lykke, K. R., Hunt, J. E., Pellin, M. J., Hemminger, J. C.. Gruen, D. M. \& Stock, L. M. J. Amer. Chem. Soc. 113, 7499-7503 (1991).

13. Fink, J., Muller-Heinzerling, T., Pfluger, J., Bubenzer, A., Koidl, K., \& Crecelius, G. Solid State Communications 47, 687-691 (1983).

14. Robins, L. H., Farabaugh, E. N. \& Feldman, A. J. Mater. Res. 5, 2456-2468 (1990).

15. Yarbrough, W. A. \& Messier, R. Science 247, 688-696 (1990).

16. For a recent review see Gruen, D. Nucl. Instr. Mathods in Physics Res. B78, 118 (1993).

17. Meilunas, R., Chang, R. P. H., Liu, S. \& Kappes, M. M. Nature 354, 271 (1991).

18. Meilunas, R., Chang, R. P. H., Liu, S. \& Kappes, M. M. Appl. Phys. Lett. 59, 3461 $3463(1991)$.

ACKNOWLEDGEMENTS. We wish to thank Dr. Mark A. Beno for the use X-ray diffractometer equipment. We would also like to acknowledge the U.S. Department of Energy, Division of Advanced Energy Projects for funding support under Contract W-31-109-ENG-38.

\section{Figure Captions}

Figure $1 \mathrm{X}$-ray diffraction pattern using $\mathrm{Cu} \mathrm{K} \alpha$ radiation for a typical film grown from a fullerene-Ar microwave plasma. All three diamond reflection peaks, corresponding to (111), (220) and (311) respectively, in the scanned range are clearly observed. No indication of a graphitic phase is found.

Figure 2 Plan-view TEM micrograph with a selected area electron diffraction pattern as an inset. The difference in contrast between individual grains reflects the differenece in crystal orientation with respect to the incident electron beam. The inset diffraction pattern was taken from the area shown in the figure and can be fully indexed to the face-centered cubic diamond lattice with a lattice constant of $3.53 \AA$. Note that no graphitic diffraction pattern is observed, demonstrating the absence of a graphitic phase.

Figure 3 TEM micrograph of two diamond grains with common $<110>$ orientation (we believe that they were developed from a single original crystal) and the corresponding electron diffraction pattern (inset). Note that twinning occurs only in the vicinity of the grain boundary between the crystals.

Figure 4 EELS spectrum showing carbon near K-edge structure of diamond films. The absorption peak at $291 \mathrm{eV}$ is characteristic of diamond. No graphitic or amorphous components are observed. 
Figure 5 Raman spectrum showing a peak at $1333 \mathrm{~cm}^{-1}$ and a broad band around $1550 \mathrm{~cm}^{-1}$. The $1333 \mathrm{~cm}^{-1}$ peak is characteristic of diamond films and $1550 \mathrm{~cm}^{-1}$ band is also commonly observed for small grain size films. 


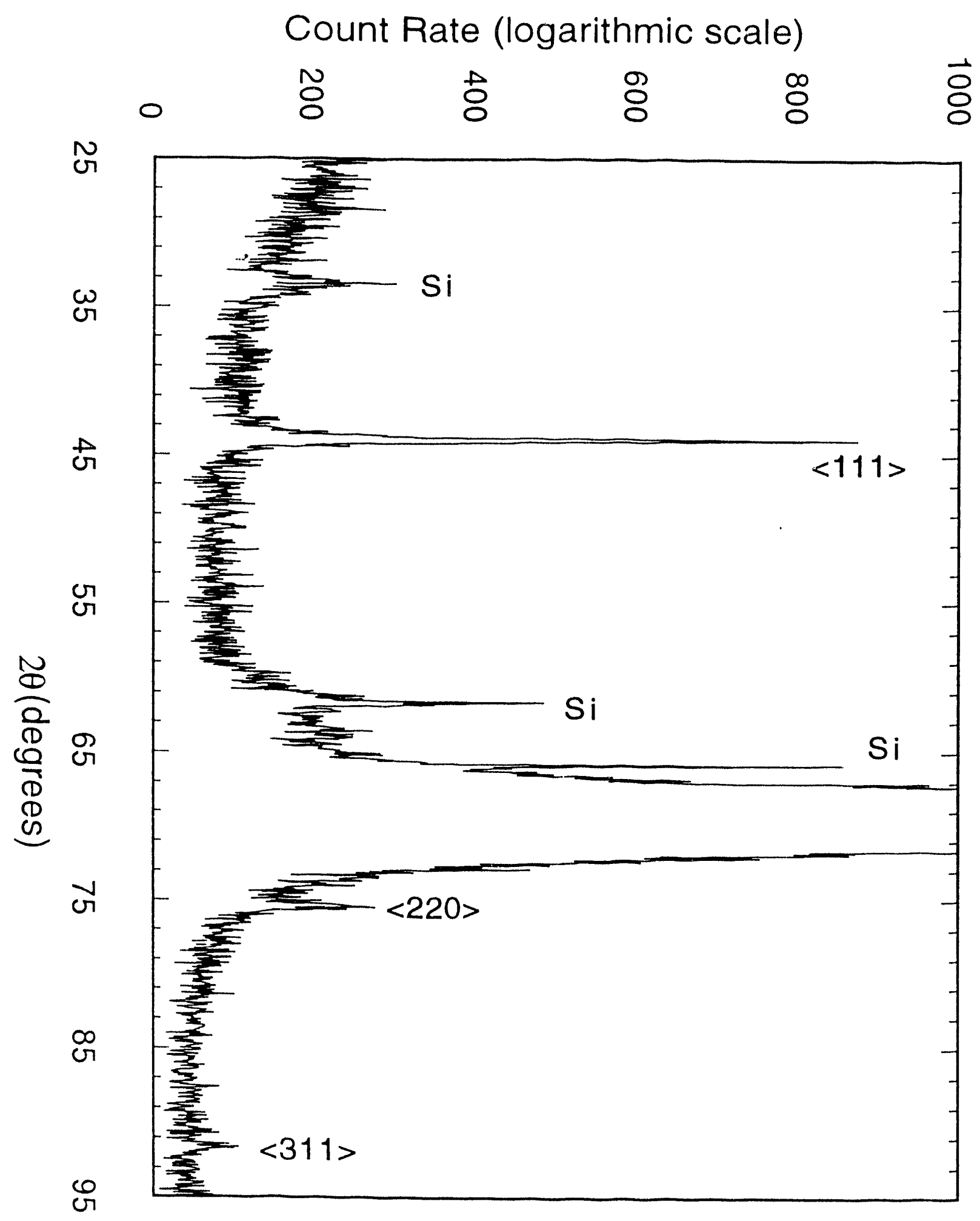




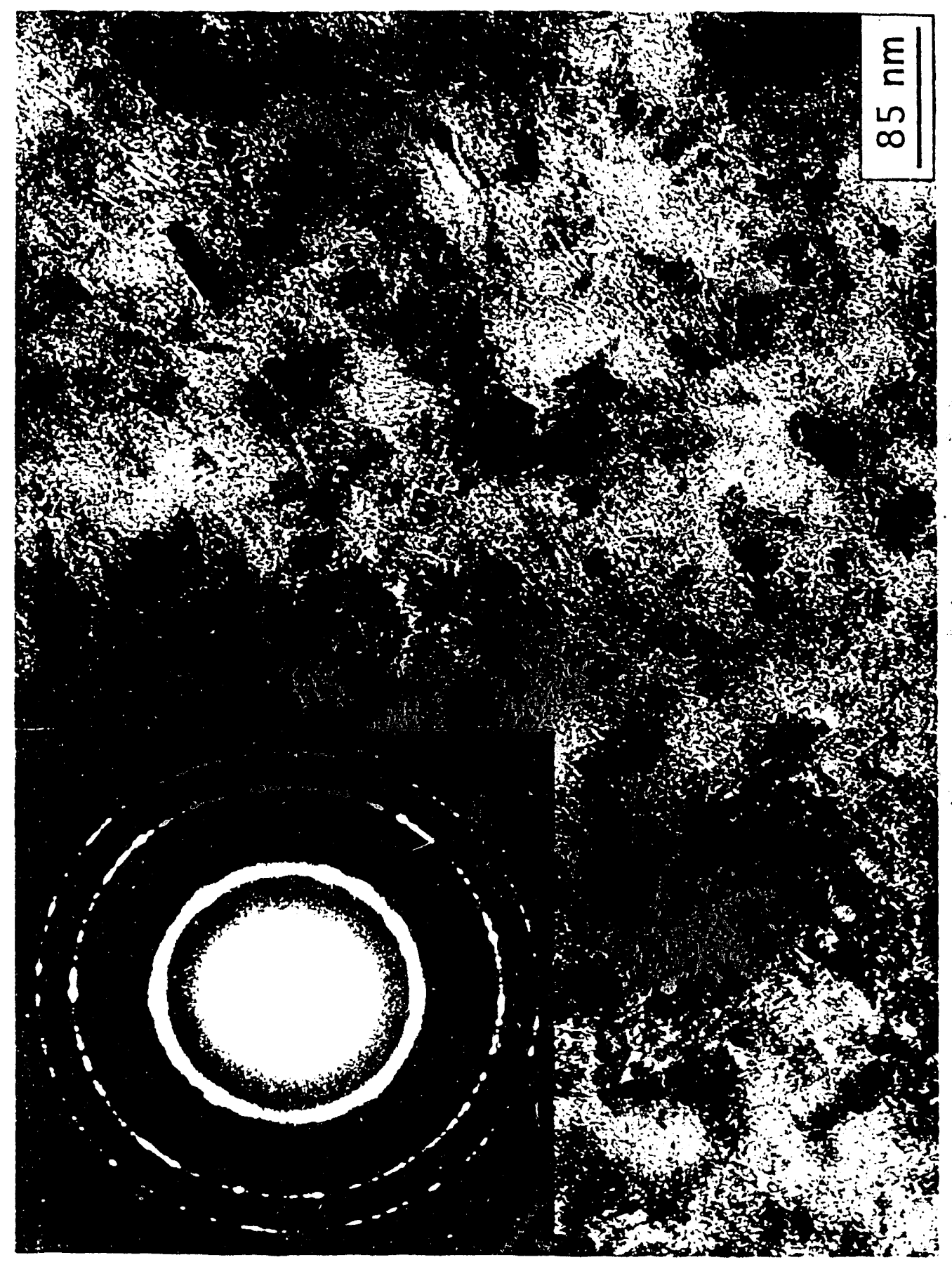




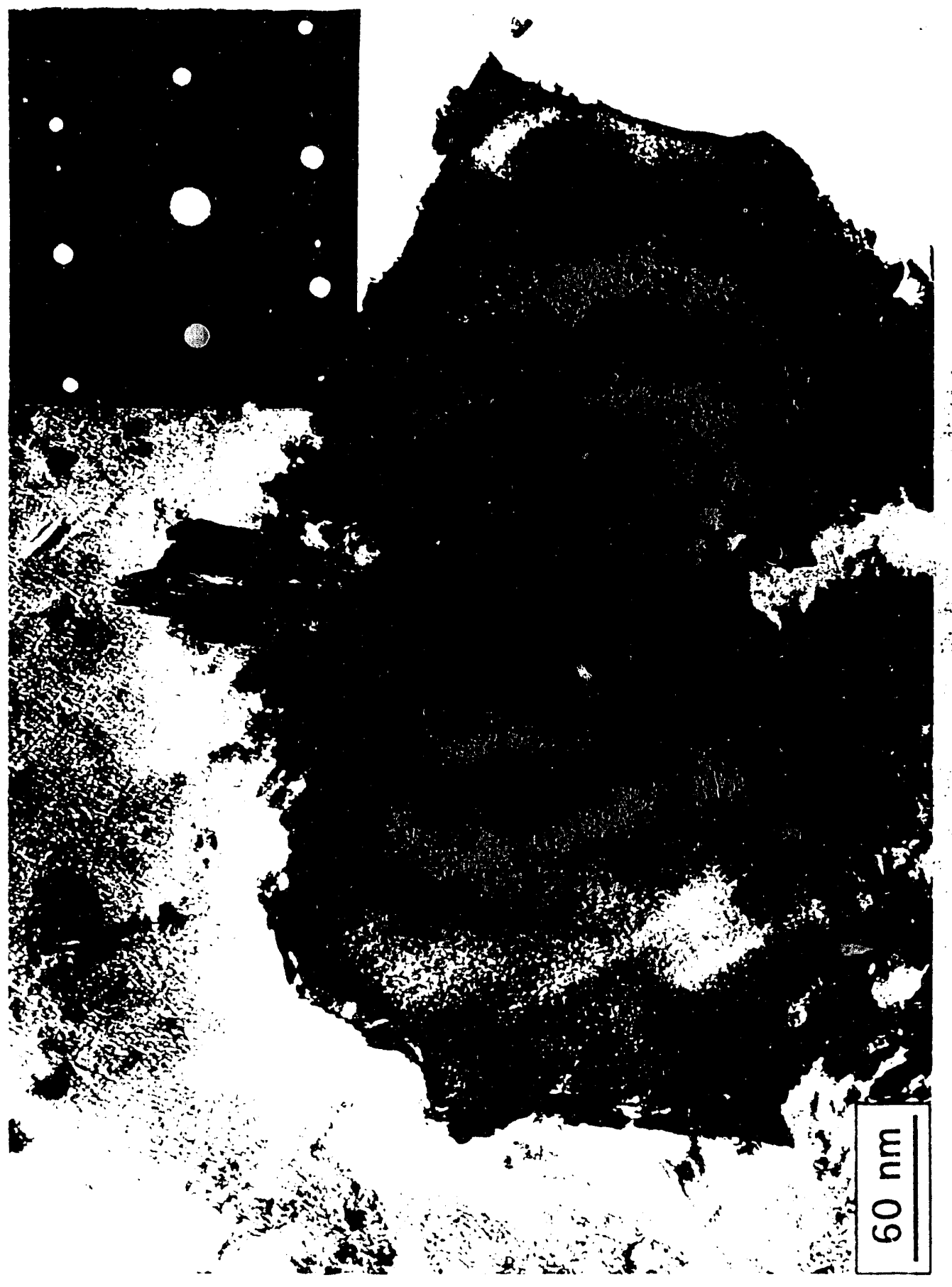




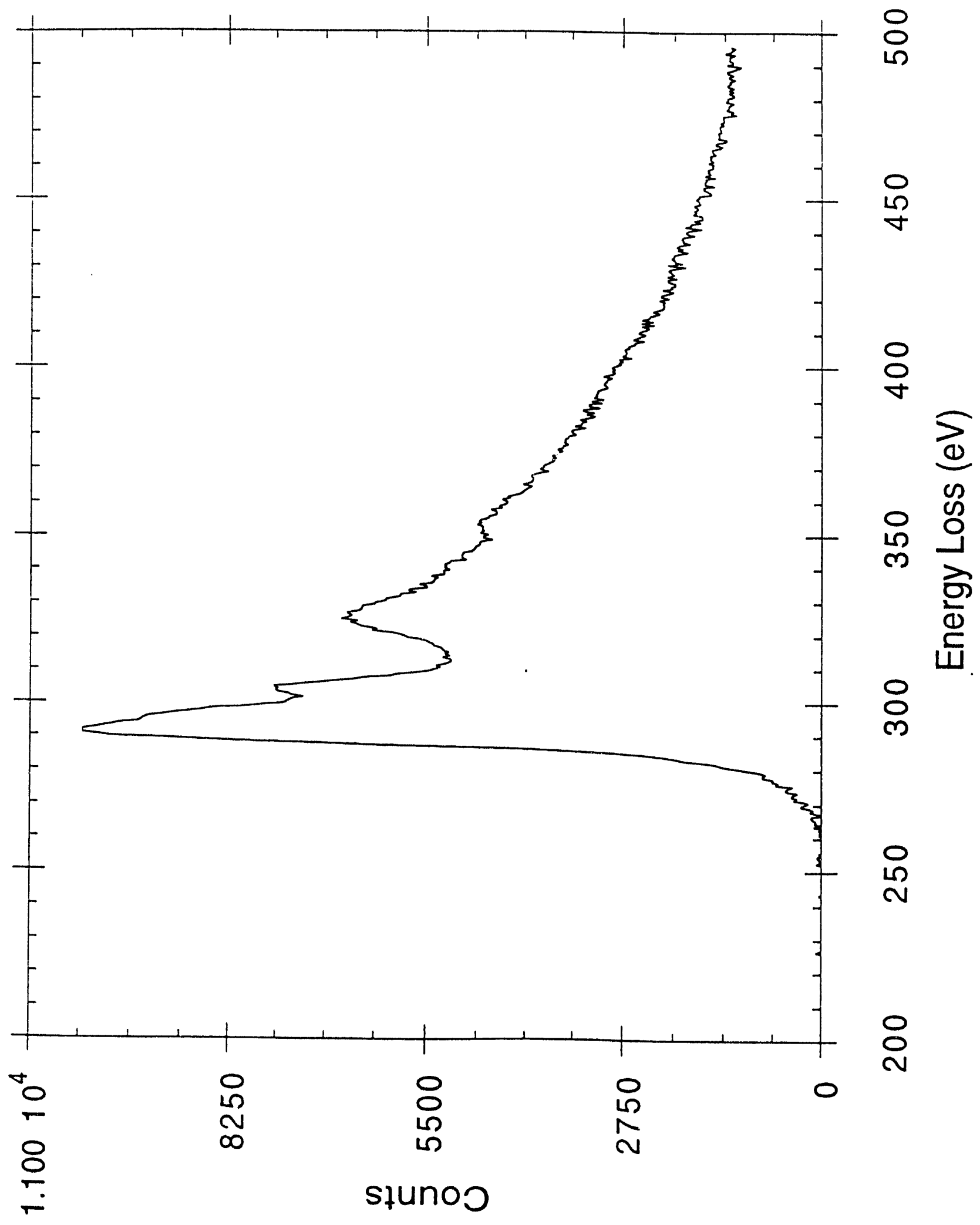




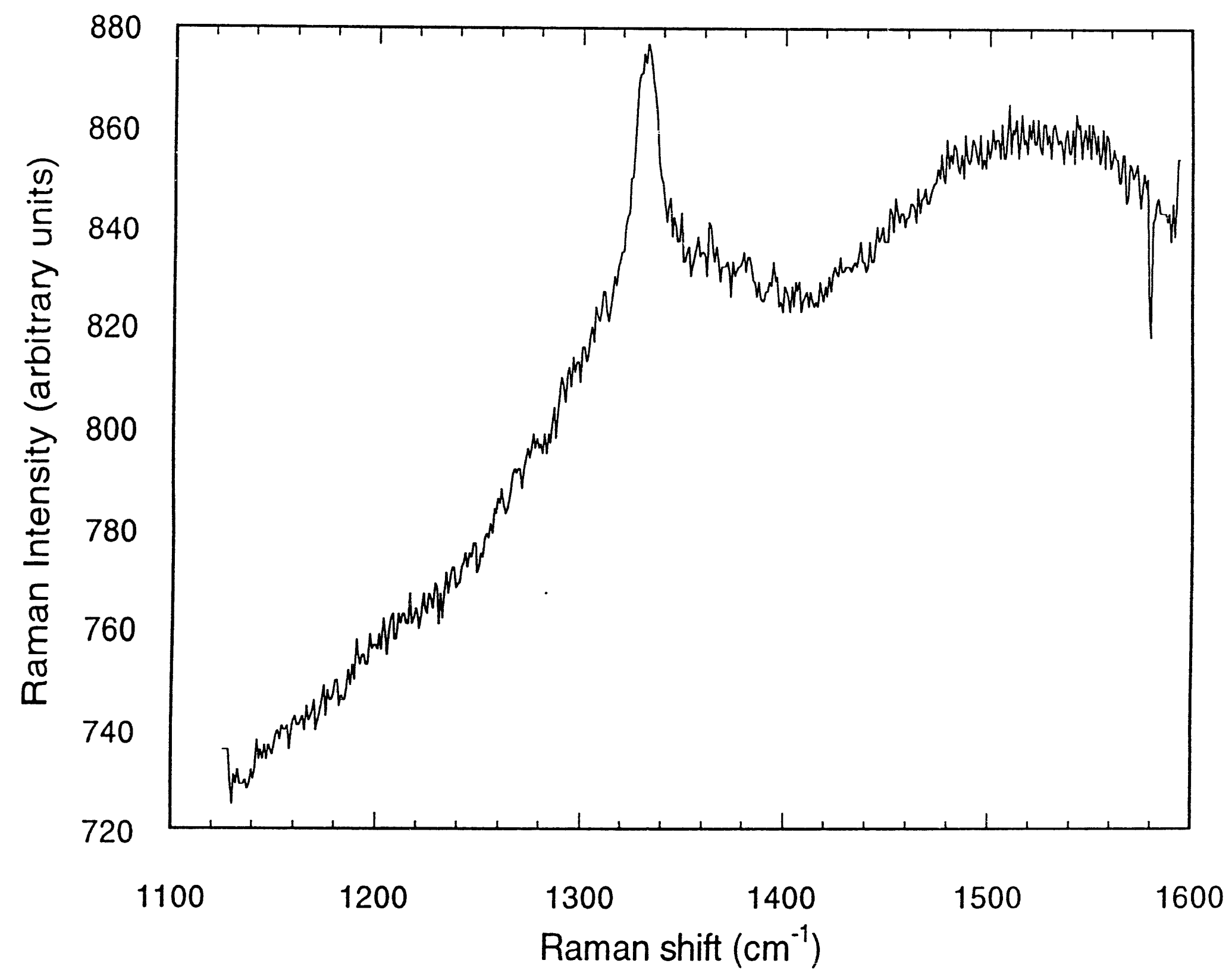



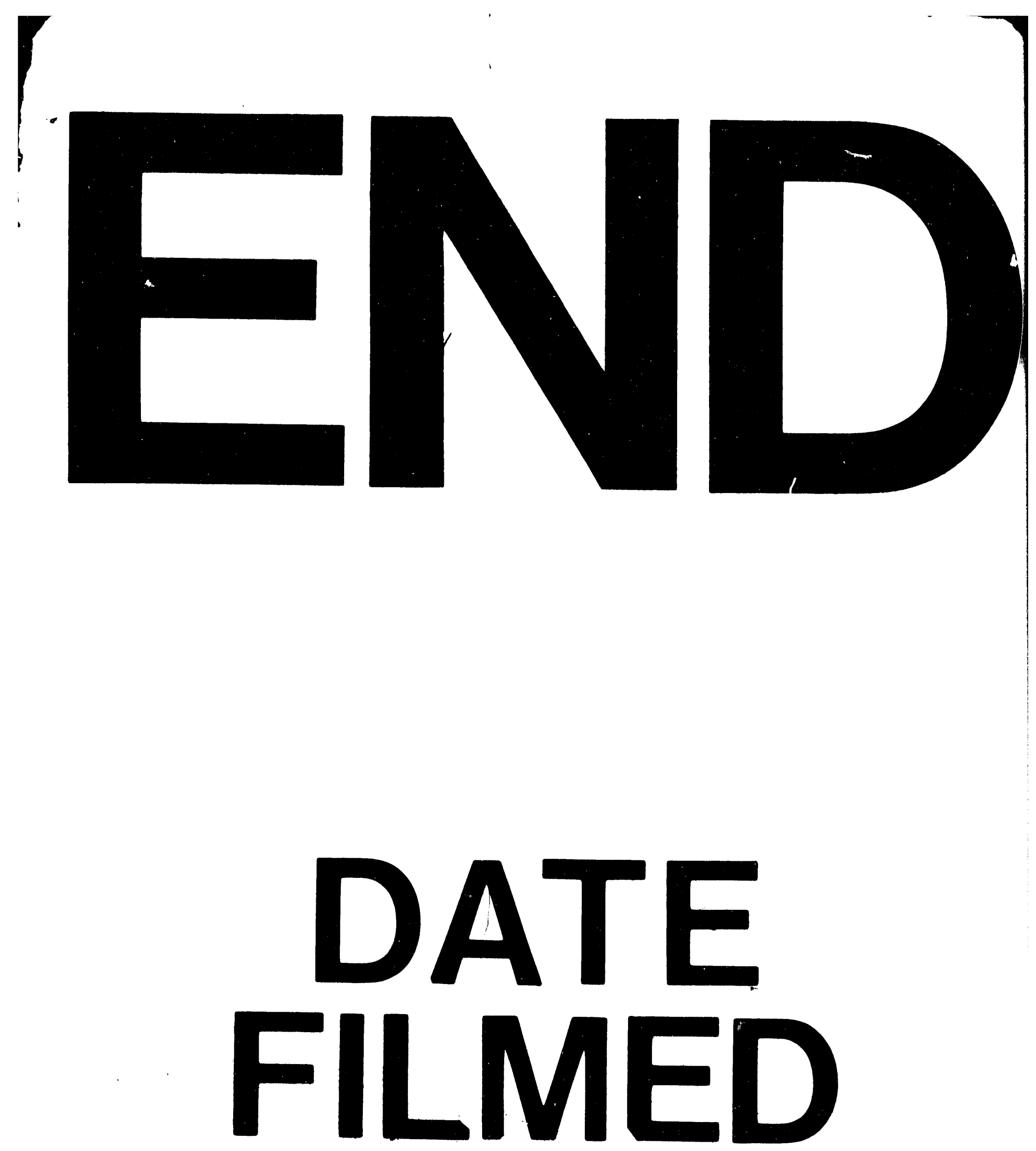

1

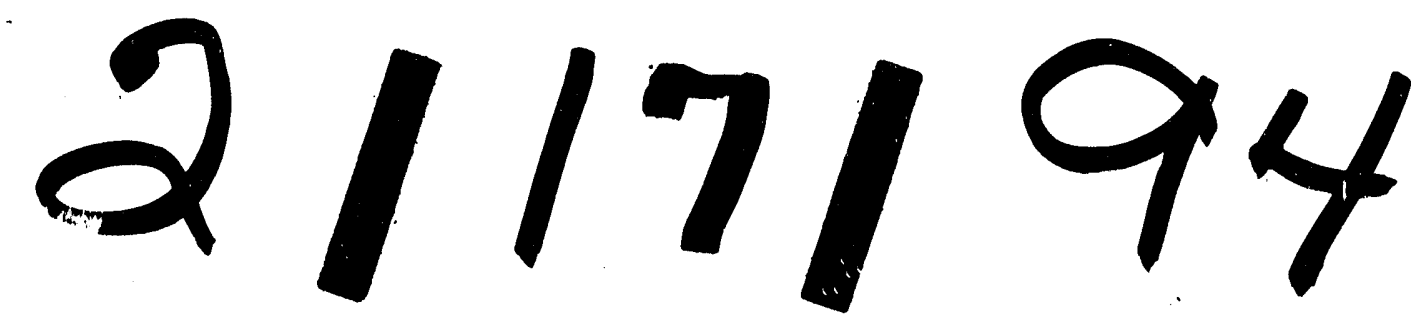


